\title{
Granulocyte growth factor use in elderly patients with non-Hodgkin's lymphoma in the United States: adherence to guidelines and comparative effectiveness
}

\author{
Linda S. Elting ${ }^{1} \cdot$ Ying Xu $^{1}$ • Mariana Chavez-MacGregor ${ }^{1} \cdot$ Sharon H. Giordano ${ }^{1}$
}

Received: 5 November 2015 / Accepted: 3 January 2016/Published online: 21 January 2016

(C) Springer-Verlag Berlin Heidelberg 2016

\begin{abstract}
Purpose The efficacy of prophylactic granulocyte colonystimulating factors (G-CSFs) among elderly patients with non-Hodgkin's lymphoma (NHL) receiving CHOP-based chemotherapy has been demonstrated in clinical trials, and G-CSFs are recommended in guidelines. We studied guideline adherence and the effectiveness of G-CSFs in the general population.

Methods We used inpatient and outpatient claims from nationally representative databases linked to cancer information from tumor registries. Patients $(N=5884)$ diagnosed with NHL between 2001 and 2007 who were older than 65 years and who received CHOP-based chemotherapy were included. Adherence to guidelines was measured as the use of GCSFs within 7 days of the first dose of chemotherapy. The measures of effectiveness were fever, infection, and death during cycle 1 of chemotherapy and time to cycle 2. Multiple-variable models of these outcomes were developed using logistic regression, controlling for demographic, clinical, and provider factors.

Results G-CSF use increased from $32 \%$ in 2001 to $72 \%$ in 2007. Patients who received G-CSFs were significantly less likely to have outpatient encounters for infection than those
\end{abstract}

Electronic supplementary material The online version of this article (doi:10.1007/s00520-016-3079-4) contains supplementary material, which is available to authorized users.

Linda S. Elting

lelting@mdanderson.org

1 Department of Health Services Research, The University of Texas MD Anderson Cancer Center, 1515 Holcombe Blvd. Unit 1444, Houston, TX 77030, USA who did not receive early G-CSFs (35 vs $47 \%$; $p<0.0001$ ). Inpatient encounters for infection were similarly prevalent among patients who did or did not receive early G-CSFs (5 vs $4 \% ; p=0.2$. There was no association between G-CSF use and death during cycle 1 .

Conclusions Adherence to guidelines increased after publication of clinical trials and exceeded $70 \%$ after publication of guidelines. G-CSFs were effective in preventing outpatient encounters for fever or infection, but not inpatient encounters or deaths during cycle 1 .

Keywords Granulocyte growth factors · Febrile neutropenia · Guideline adherence $\cdot$ SEER-Medicare

\section{Introduction}

Chemotherapy provides significant survival benefit for elderly patients with non-Hodgkin's lymphoma (NHL), despite the increased risk of adverse effects among these patients [1-7]. In particular, elderly patients are at increased risks of prolonged and profound neutropenia as well as lifethreatening outcomes of infections [8-10]. These outcomes lead to reduced dose intensity and effectiveness of chemotherapy $[11,12]$. Clinical trials have shown that administration of prophylactic granulocyte colony-stimulating factors (G-CSFs) improves relative dose intensity and reduces the rate of neutropenic infection in this population [13-15]. These findings, published a decade ago, led to specific recommendations from ASCO and NCCN for prophylactic use of G-CSFs among elderly patients receiving doxorubicin-based chemotherapy $[16,17]$. We studied prophylactic utilization of G-CSFs before and after guidelines were published, in a nationally representative sample of elderly patients with NHL in the USA. We also studied the effectiveness of G-CSFs by examining their 
impact on the rates of infection and death, the duration of a chemotherapy cycle, and the costs of inpatient and outpatient visits for infection.

\section{Methods}

This study was approved by the Institutional Review Boards of MD Anderson Cancer Center and the Texas Department of State Health Services.

Data sources and patient population The study cohort was drawn from the 2010 linked Surveillance, Epidemiology, and End Results (SEER)-Medicare and Texas Cancer Registry (TCR)-Medicare data, which cover 17 geographic areas in the USA and the state of Texas, respectively. The SEER program collects data from tumor registries covering $28 \%$ of the US population [18]. The Medicare program covers $97 \%$ of the US population age 65 years or older. SEER cancer cases are matched with their Medicare claims using a probabilistic linkage method; $94 \%$ of those diagnosed with cancer at age 65 years or older are matched with their Medicare enrollment records [19]. The TCR is the fourth largest statewide population-based registry in the USA and is a component of the Texas Department of State Health Services. The TCR is not included among the SEER registries, but it collects data using standardized registry rules and is Gold Certified by the North American Association of Central Cancer Registries. For this study, cases from the TCR were linked with Texas Medicare claims by the same contractor using the same probabilistic linkage method as the SEER-Medicare linkage.

Cancer cases diagnosed between January 1, 2001, and December 31, 2007, and Medicare claims through December 31, 2008, were included. These years were chosen to provide 3 years' data before and after the year (2004) in which growth factors were recommended for this population by NCCN. The databases provided demographic (e.g., age gender, race, year of diagnosis), clinical (e.g., tumor histologic type, ICD-9 diagnosis, grade, and stage), socioeconomic (e.g., metropolitan area and geographic region of patient's residence) and health provider (e.g., facility and specialty type) information on Medicare-eligible patients with cancer.

We identified patients who were diagnosed with diffuse large B cell lymphoma between January 1, 2001, and December 31, 2007, using tumor site (codes 71 and 72), lymphoma subtype (codes 13-17), and histology type (codes 9679, 9680, and 9684). We excluded patients who had other cancers and those who were diagnosed at death. Patients represented in TCR-Medicare data were excluded if they were not residents of Texas at the time of diagnosis. To ensure a complete year of claims from which to calculate a comorbidity score at baseline, we further excluded the patients younger than 66 years at diagnosis, those who did not have continuous Medicare Parts A and B enrollment, and those who were enrolled in Medicare Advantage HMOs during the 12 months before the diagnosis (See Appendix 1-Supplemental Information).

We examined the use of G-CSFs, infections, and resource utilization during only the first cycle of doxorubicin therapy after diagnosis. Thus, our final cohort was restricted to patients who had received doxorubicin-based chemotherapy (identified by HCPCS codes J9000, J9001, J9178, J9180, and C9415) within 6 months of diagnosis and those with continuous enrollment in Medicare Parts A and B, but no HMO enrollment, between diagnosis and 2 months after the chemotherapy.

Outcomes There were two primary outcomes of interest, receipt of prophylactic granulocyte growth factors and subsequent development of infection. Because it is not possible to determine the intent of growth factor prescription (prophylactic vs therapeutic) using claims, we examined receipt of G-CSFs early in cycle 1 , which was defined as a claim for a G-CSF within 7 days of initiation of doxorubicin-based chemotherapy. The 7-day period allowed for administration of a G-CSF 13 days after either standard CHOP regimens or 4-day regimens commonly used among frail elderly patients and those with reduced ejection fraction (122 patients, $3.7 \%$ of the sample). The G-CSFs included were filgrastin, pegfilgrastin, and sargramostin, which were identified by HCPCS codes J1440, J1441, C9119, J2505, Q4053, S0135, and J2820. Patients whose G-CSFs were initiated later in the cycle were included in the cohort, but not considered to have received early GCSFs. Infections were identified by inpatient or outpatient claims for documented infections or fever ICD-9 diagnosis codes (1-135, 465, 466, 480-486, 487.0-487.8, 490, 595.0, $595.89,595.9,681,682,780.60,780.61$, and 790.7$)$ or HCPCS codes (90780, 90781, 90788, S9494, S9497, S9500, S9501, S9502, S9503, and S9504) during cycle 1.

We studied three secondary outcomes including death during cycle 1 , the costs of inpatient and outpatient infectionrelated visits, and the mean number of days until cycle 2 . Cost was measured from the payor's (Medicare's) perspective in 2015 US dollars. Payments for infection-related visits were inflated to 2015 US dollars using the medical care component of the Consumer Price Index. Payments for outpatient antibiotics were not included because these were not covered by Medicare for much of the study period. Costs related to cancer therapy (chemotherapy, visits for follow-up, or other clinical problems) were not included. The cost of growth factors was not examined in this study.

Covariates Anticipating variation in case mix in this observational study, we accounted for available demographic, clinical, socioeconomic, and practice or 
provider variables. Demographic covariates included age $(<70,70-79,80-85$, and $>85$ years $)$, gender, race (white, black, and others), ethnicity (Hispanic and nonHispanic), and year of diagnosis. Clinical covariates included Charlson Comorbidity Index $(0-1$, and $\geq 2)$ and chemotherapy with rituximab (yes/no, identified by claims with HCPCS code J9310). Socioeconomic covariates included geographic region (Midwest, Northeast, South and West), metropolitan area residence (yes/no), the percent of persons age 25 years or older with a high school education in the census tract (grouped by quartile), and the percent of people living below the poverty level in the census tract (grouped by quartile).

Practice and provider covariates included facility type (institution based vs non-institution based), provider specialty type (hematology, internal medicine, medical oncology, and others), and the provider's annual care volume ( $\geq 3$ vs $<3$ elderly NHL patients treated with chemotherapy). The facility and provider of interest were those associated with the claim for the cycle 1 chemotherapy doses, that is, where and by whom the chemotherapy was prescribed. The provider's annual care volume was the number of patients in the study cohort who were cared for by each physician during the year of the patient's initial cycle of chemotherapy.

Analysis We first described and compared the characteristics of the SEER-Medicare and TCR-Medicare samples. Because these characteristics did not differ in significant ways, we combined these samples for the remaining analyses. Using the combined sample, we then examined the association between early G-CSF use and each of the covariates with chi-square tests. We also explored the time trend of percentage of patients receiving early G-CSF using Cochran-Armitage tests. Based on the results of the univariate analysis, we applied multivariate logistic regression to model the likelihood of receiving early G-CSF, only including patients' demographic covariates and the covariates with a $p$ value $\leq 0.20$ in the univariate analysis in the final model.

Next, we examined the association between early GCSF and the likelihood of outpatient and inpatient visits for infection using logistic regression, controlling for confounding factors. Similarly, the covariates in the final model included all demographic variables and the covariates with a $p$ value of 0.20 or less in the univariate analysis. We also tested for interaction between early G-CSF treatment and other covariates.

All analyses were conducted using SAS v9.3 (SAS Institute, Cary NC). Parameter estimates from logistic regression models were reported as odds ratios, $95 \%$ confidence interval (CI), and $p$ values.

\section{Results}

The study population consisted of 5884 elderly patients with NHL, of whom 757 (13\%) were from Texas. Differences between the Texas and SEER populations reflected the demographic composition of Texas, with higher proportions of patients who were Hispanics (16.6 vs $5.8 \% ; p<0.001)$ and patients who lived in areas with high rates of poverty and lower education (Table 1). Fewer patients in Texas lived in metropolitan areas ( 75.8 vs $83.8 \% ; p<0.0001)$. Fifteen percent of patients in Texas had "state buy in," a benefit available to low-income persons, compared with only $11 \%$ of SEER patients $(p=0.009)$. Patients in the two groups were similarly likely to be treated by hematologists and oncologists, although the physicians in Texas treated fewer elderly patients with NHL $(p=0.005)$ and fewer who received chemotherapy annually $(p<0.0001)$ than patients in the SEER population. More than $90 \%$ of patients received rituximab in both the SEER and Texas populations. Importantly, the patients in Texas and SEER regions did not differ with respect to the prevalence of high comorbidity scores (12.6 and $13.0 \%$, respectively; $p=0.77$ ), and based upon this finding, the groups were combined for all subsequent analyses.

Factors associated with early growth factor use Over the 7year period, $56 \%$ of patients received early G-CSFs during cycle 1 ; however, the prevalence of use varied significantly over time, from $32 \%$ in 2001 to $72 \%$ in 2007 (Table 2). In univariate analysis, older patients (60 vs $52 \%$; $p<0.001)$ and those with higher comorbidity scores (60 vs $55 \%$; $p=0.02$ ) were more likely to receive early G-CSF as were those who lived in metropolitan ( 57 vs $52 \% ; p=0.004)$ counties and those with lower rates of poverty ( 59 vs $52 \% ; p=0.0003$ ). Most patients $(91 \%)$ received rituximab as a part of their CHOP-based chemotherapy. The 519 patients who did not receive rituximab were significantly less likely to receive early G-CSFs ( 47 vs $57 \% ; p<0.0001$ ). There were no statistically significant differences in the use of G-CSF by gender, race, or ethnicity. State buy-in, a marker for low income, was not associated with G-CSF use.

Hematologists $(60 \%)$ were significantly more likely to prescribe G-CSF than medical oncologists (55\%), internists (53\%), and those from other or unknown specialties (54\%) $(p=0.0012)$ (Table 2). High-volume providers and those who treated more elderly patients with chemotherapy were no more likely to prescribe G-CSF than their lower-volume counterparts. The highest rates of early G-CSF use were observed in Connecticut (64\%), Atlanta (63\%), San Francisco (62\%), and New Jersey (61\%) while the lowest rates were observed in Texas $(53 \%)$ and Seattle $(50 \%)$ and Iowa (49 \%) $(p<0.001)$.

In multiple-variable analysis, the year of treatment was most significantly associated with early G-CSF use, with a 
Table 1 Characteristics of TexasMedicare and SEER-Medicare populations

\begin{tabular}{|c|c|c|c|}
\hline Characteristic & $\begin{array}{l}\text { TX-Medicare } \\
N=757 \\
N(\%)\end{array}$ & $\begin{array}{l}\text { SEER-Medicare } \\
N=5127 \\
N(\%)\end{array}$ & $p$ value \\
\hline \multicolumn{4}{|l|}{ Demographic characteristics } \\
\hline Age $<70$ years & $165(21.80 \%)$ & $1006(19.62 \%)$ & 0.0633 \\
\hline Age $70-74$ years & $233(30.78 \%)$ & $1421(27.72 \%)$ & \\
\hline Age $75-79$ years & $179(23.65 \%)$ & $1361(26.55 \%)$ & \\
\hline Age $\geq 80$ years & $180(23.78 \%)$ & $1339(26.12 \%)$ & \\
\hline Female & $414(54.69 \%)$ & $2706(52.78 \%)$ & 0.3297 \\
\hline White & $710(93.79 \%)$ & $4696(91.59 \%)$ & 0.0041 \\
\hline Black & $27(3.57 \%)$ & $154(3.00 \%)$ & \\
\hline Others & $20(2.64 \%)$ & $277(5.04 \%)$ & \\
\hline Hispanic & $126(16.64 \%)$ & $297(5.79 \%)$ & $<0.001$ \\
\hline \multicolumn{4}{|l|}{ Clinical characteristics } \\
\hline Comorbidity score $\geq 2$ & $95(12.55 \%)$ & $665(12.97 \%)$ & 0.7719 \\
\hline Rituximab treatment & $707(93.39 \%)$ & $4658(90.85 \%)$ & 0.0196 \\
\hline \multicolumn{4}{|l|}{ Socioeconomic characteristics } \\
\hline Median \% less than high school education ${ }^{\mathrm{a}}$ & 22.58 & 13.75 & \\
\hline Median $\%$ college graduates ${ }^{\mathrm{a}}$ & 16.01 & 23.93 & $<0.0001$ \\
\hline Median $\%$ below poverty line ${ }^{a}$ & 12.86 & 7.11 & $<0.0001$ \\
\hline Metropolitan county residence & $574(75.83 \%)$ & $4297(83.81 \%)$ & $<0.0001$ \\
\hline State buy-in & $110(14.53 \%)$ & $575(11.22 \%)$ & 0.0090 \\
\hline \multicolumn{4}{|l|}{ Practice/provider characteristics } \\
\hline Facility $=$ institution & $490(64.73 \%)$ & $2963(57.79 \%)$ & 0.0003 \\
\hline \multicolumn{4}{|l|}{ Board certification: } \\
\hline Hematology & $190(25.10 \%)$ & $1281(24.99 \%)$ & \\
\hline Medical oncology & $342(45.18 \%)$ & $2423(47.26 \%)$ & 0.5806 \\
\hline Internal medicine & $66(8.72 \%)$ & $388(7.57 \%)$ & \\
\hline Other/unknown ${ }^{\mathrm{b}}$ & $159(21.00 \%)$ & $1035(20.19 \%)$ & \\
\hline \multicolumn{4}{|l|}{ Number elderly NHL pts treated } \\
\hline$<3$ pts per year & $642(84.81 \%)$ & $4128(80.51 \%)$ & 0.0046 \\
\hline$\geq 3$ pts per year & $115(15.19 \%)$ & $999(19.49 \%)$ & \\
\hline \multicolumn{4}{|l|}{ Number elderly NHL pts receiving chemo } \\
\hline$<3$ pts per year & $670(88.51 \%)$ & $4210(82.11 \%)$ & $<0.0001$ \\
\hline$\geq 3$ pts per year & $87(11.49 \%)$ & $917(17.89 \%)$ & \\
\hline
\end{tabular}

${ }^{\text {a }}$ Census tract data, and 35 patients with missing value

${ }^{b}<11$ patients with unknown specialty type; exact number suppressed to protect confidentiality four- to sixfold increase in G-CSF use in 2004 and subsequent years $(p<0.0001)$ (Table 2). Patients over 75 years of age also were more likely to receive early G-CSFs $(p<0.001)$. Patients who were not treated in the Northeast region of the USA were less likely to receive early G-CSF, particularly those in the Midwest (odds ratio $(\mathrm{OR})=0.64 ; p<0.001$ ) and Texas $(\mathrm{OR}=0.71 ; p=0.002)$. Practice differed by region of the country in every year studied, suggesting that the observed differences were due to actual practice variation, not to rapid adoption of recommendations in one or more regions (data not shown). Patients who were not treated in institution-based practices were significantly less likely to receive early G$\mathrm{CSF}(\mathrm{OR}=0.79 ; p<0.0001)$ compared with those who were treated in institution-based practices. Interestingly, patients with high comorbidity scores were not significantly more likely to receive early G-CSF in this analysis.

Outcomes Overall, $40 \%$ of patients had an encounter for fever or infection during cycle 1 ; the vast majority $(94 \%)$ of these occurred in the outpatient setting. Patients who received early G-CSFs were significantly less likely to have an encounter for infection than those who did not receive early G-CSFs ( 35 vs $47 \% ; p<0.0001$ ) (Table 3 ). This difference was limited to outpatient encounters; inpatient encounters for infection were similarly prevalent among patients who did or did not receive early G-CSFs ( 5 vs $4 \% ; p=0.2$ ). The median number 
Table 2 Probability of receiving early G-CSF (TCR + SEER combined)

\begin{tabular}{|c|c|c|c|c|c|}
\hline Factor & $\begin{array}{l}\text { Number } \\
\text { of patients }\end{array}$ & $\%$ with early G-CSF (95 \% CI) & $\begin{array}{l}\text { Univariate } \\
p \text { value }\end{array}$ & Multivariate (MV) odds ratio $(95 \% \mathrm{CI})$ & MV $p$ value \\
\hline \multicolumn{6}{|l|}{ Age (years) } \\
\hline$<70$ & 1171 & $50 \%(47-53 \%)$ & \multirow[t]{4}{*}{$<0.0001$} & Referent & 0.3053 \\
\hline $70-74$ & 1654 & $53 \%(50-55 \%)$ & & $1.09(0.93-1.28)$ & 0.0015 \\
\hline $75-79$ & 1540 & $57 \%(54-59 \%)$ & & $1.31(1.11-1.55)$ & $<0.0001$ \\
\hline$\geq 80$ & 1519 & $63 \%(60-65 \%)$ & & $1.55(1.31-1.84)$ & \\
\hline \multicolumn{6}{|l|}{ Race } \\
\hline White & 5406 & $56 \%(55-57 \%)$ & \multirow[t]{3}{*}{0.8037} & Referent & 0.9884 \\
\hline Black & 181 & $54 \%(46-61 \%)$ & & $1.0(0.72-1.39)$ & 0.7485 \\
\hline Others & 297 & $56 \%(50-62 \%)$ & & $0.96(0.73-1.25)$ & \\
\hline \multicolumn{6}{|l|}{ Sex } \\
\hline Male & 2764 & $56 \%(54-58 \%)$ & \multirow[t]{2}{*}{0.6547} & Referent & \multirow[t]{2}{*}{0.8613} \\
\hline Female & 3120 & $56 \%(54-57 \%)$ & & $0.99(0.88-1.11)$ & \\
\hline \multicolumn{6}{|l|}{ Ethnicity } \\
\hline Non-Hispanic & 5383 & $56 \%(55-57 \%)$ & \multirow[t]{3}{*}{0.3989} & Referent & 0.8351 \\
\hline Hispanic & 432 & $55 \%(50-60 \%)$ & & $0.98(0.77-1.23)$ & \multirow{2}{*}{0.6762} \\
\hline Unknown & 69 & $64 \%(51-75 \%)$ & & $1.12(0.65-1.95)$ & \\
\hline \multicolumn{6}{|l|}{ Comorbidity score } \\
\hline $0-1$ & 5124 & $55 \%(54-57 \%)$ & \multirow[t]{2}{*}{0.0209} & Referent & \multirow[t]{2}{*}{0.2010} \\
\hline$\geq 2$ & 760 & $60 \%(56-63 \%)$ & & $1.12(0.94-1.33)$ & \\
\hline \multicolumn{6}{|l|}{ State buy-in } \\
\hline Yes & 685 & $54 \%(51-58 \%)$ & \multirow[t]{2}{*}{0.3903} & \multirow[t]{2}{*}{ Not tested } & \\
\hline No & 5199 & $56 \%(55-58 \%)$ & & & \\
\hline \multicolumn{6}{|l|}{ Residence } \\
\hline Metropolitan & 4871 & $57 \%(55-58 \%)$ & 0.0035 & Referent & 0.1982 \\
\hline Non-metropolitan countries & 1013 & $52 \%(49-55 \%)$ & & $0.90(0.76-1.06)$ & \\
\hline Rituximab & & & & & \\
\hline Yes & 5365 & $57 \%(56-58 \%)$ & $<0.0001$ & Referent & 0.4671 \\
\hline No & 519 & $47 \%(43-51 \%)$ & & $0.93(0.76-1.13)$ & \\
\hline Quartile of $\%$ persons $25+$ less & than high sch & ool education ${ }^{\mathrm{a}}$ & & & \\
\hline$\leq 8.17 \%$ & 1465 & $60 \%(57-62 \%)$ & 0.0023 & 1.00 & 0.1313 \\
\hline $8.18-14.53 \%$ & 1462 & $55 \%(52-57 \%)$ & & $0.88(0.74-1.04)$ & 0.9916 \\
\hline $14.54-24.56 \%$ & 1460 & $56 \%(54-59 \%)$ & & $1.00(0.83-1.21)$ & 0.5496 \\
\hline$>24.56 \%$ & 1462 & $53 \%(50-56 \%)$ & & $0.93(0.73-1.18)$ & \\
\hline Quartile of $\%$ persons $25+$ with & some colleg & education ${ }^{\mathrm{a}}$ & & & \\
\hline$\leq 13.02 \%$ & 1464 & $53 \%(50-55 \%)$ & 0.0212 & Not tested in MV analysis due to & \\
\hline $13.03-22.92 \%$ & 1461 & $55 \%(53-58 \%)$ & & collinearity with factor below & \\
\hline $22.93-39.60 \%$ & 1462 & $57 \%(54-60 \%)$ & & & \\
\hline$>39.60 \%$ & 1462 & $58 \%(56-61 \%)$ & & & \\
\hline Quartile of tract residents living & below pover & y level ${ }^{\mathrm{a}}$ & & & \\
\hline$\leq 4.13 \%$ & 1465 & $59 \%(56-61 \%)$ & 0.0003 & Referent & 0.4707 \\
\hline $4.14-7.69 \%$ & 1463 & $58 \%(56-61 \%)$ & & $1.07(0.90-1.27)$ & 0.8394 \\
\hline $7.70-14.31 \%$ & 1461 & $55 \%(52-57 \%)$ & & $0.98(0.80-1.20)$ & 0.3039 \\
\hline$>14.31 \%$ & 1460 & $52 \%(49-55 \%)$ & & $0.88(0.69-1.13)$ & \\
\hline Facility & & & & & \\
\hline Institution based & 3453 & $58 \%(57-60 \%)$ & $<0.0001$ & Referent & $<0.0001$ \\
\hline Not institution based & 2431 & $53 \%(51-55 \%)$ & & $0.79(0.70-0.88)$ & \\
\hline Board certification & & & & & \\
\hline Medical oncology & 2765 & $55 \%(53-57 \%)$ & 0.0012 & Referent & 0.6134 \\
\hline Hematology & 1471 & $60 \%(58-63 \%)$ & & $1.04(0.90-1.19)$ & 0.2502 \\
\hline Internal medicine & 454 & $53 \%(49-58 \%)$ & & $0.88(0.71-1.09)$ & 0.6747 \\
\hline Others/unknown ${ }^{\mathrm{b}}$ & 1194 & $54 \%(51-56 \%)$ & & $0.97(0.83-1.13)$ & \\
\hline No. of elderly NHL pts treated & & & & & \\
\hline$<3$ pts per year & 4770 & $56 \%(54-57 \%)$ & 0.7886 & Not tested, univariate $p$ value $>0.20$ & \\
\hline$\geq 3$ pts per year & 1114 & $56 \%(53-59 \%)$ & & & \\
\hline Elderly pts receiving chemo & & & & & \\
\hline$<3$ pts per year & 4880 & $56 \%(54-57 \%)$ & 0.6006 & Not tested, univariate $p$ value $>0.20$ & \\
\hline$\geq 3$ pts per year & 1004 & $57 \%(54-60 \%)$ & & & \\
\hline
\end{tabular}


Table 2 (continued)

\begin{tabular}{|c|c|c|c|c|c|}
\hline Factor & $\begin{array}{l}\text { Number } \\
\text { of patients }\end{array}$ & $\%$ with early G-CSF (95 \% CI) & $\begin{array}{l}\text { Univariate } \\
p \text { value }\end{array}$ & Multivariate (MV) odds ratio $(95 \% \mathrm{CI})$ & MV $p$ value \\
\hline \multicolumn{6}{|l|}{ Tumor registry } \\
\hline San Francisco & 173 & $62 \%(54-69 \%)$ & $<0.001$ & Not tested in favor of variable below & \\
\hline Connecticut & 305 & $64 \%(59-70 \%)$ & & & \\
\hline Detroit & 380 & $56 \%(51-61 \%)$ & & & \\
\hline Hawaii & 77 & $55 \%(43-66 \%)$ & & & \\
\hline Iowa & 430 & $49 \%(44-53 \%)$ & & & \\
\hline New Mexico & 123 & $54 \%(45-63 \%)$ & & & \\
\hline Seattle & 297 & $50 \%(44-56 \%)$ & & & \\
\hline Utah & 175 & $56 \%(48-63 \%)$ & & & \\
\hline Atlanta & 133 & $63 \%(54-71 \%)$ & & & \\
\hline San Jose & 116 & $59 \%(50-68 \%)$ & & & \\
\hline Los Angeles & 355 & $59 \%(53-64 \%)$ & & & \\
\hline Rural Georgia & 11 & c & & & \\
\hline Greater California & 948 & $54 \%(51-57 \%)$ & & & \\
\hline Kentucky & 363 & $54 \%(48-59 \%)$ & & & \\
\hline Louisiana & 354 & $57 \%(51-62 \%)$ & & & \\
\hline New Jersey & 887 & $61 \%(58-65 \%)$ & & & \\
\hline Texas & 757 & $53 \%(49-56 \%)$ & & & \\
\hline \multicolumn{6}{|l|}{ Region } \\
\hline Northeast & 1192 & $62 \%(59-65 \%)$ & $<0.001$ & Referent & \\
\hline Midwest & 810 & $52 \%(48-55 \%)$ & & $0.64(0.52-0.79)$ & $<0.0001$ \\
\hline South & 861 & $56 \%(53-59 \%)$ & & $0.83(0.67-1.03)$ & 0.0947 \\
\hline West & 2264 & $55 \%(53-57 \%)$ & & $0.74(0.62-0.88)$ & 0.0006 \\
\hline Texas & 757 & $53 \%(49-56 \%)$ & & $0.71(0.57-0.88)$ & 0.0018 \\
\hline \multicolumn{6}{|l|}{ Diagnosis year } \\
\hline 2001 & 703 & $32 \%(28-35 \%)$ & $<0.0001$ & 1.00 & 0.0300 \\
\hline 2002 & 795 & $26 \%(23-30 \%)$ & & $0.78(0.62-0.98)$ & $<0.0001$ \\
\hline 2003 & 862 & $43 \%(39-46 \%)$ & & $1.59(1.28-1.96)$ & $<0.0001$ \\
\hline 2004 & 883 & $66 \%(63-69 \%)$ & & $4.25(3.43-5.28)$ & $<0.0001$ \\
\hline 2005 & 876 & $72 \%(68-75 \%)$ & & $5.53(4.43-6.90)$ & $<0.0001$ \\
\hline 2006 & 893 & $73 \%(70-76 \%)$ & & $5.86(4.70-7.32)$ & $<0.0001$ \\
\hline 2007 & 872 & $72 \%(69-75 \%)$ & & $5.50(4.40-6.88)$ & \\
\hline
\end{tabular}

a 33 patients with missing value

${ }^{\mathrm{b}}<11$ patients with unknown of the specialty type; exact number suppressed to protect confidentiality

${ }^{\mathrm{c}}$ Values suppressed due to small number of patients

of days to cycle 2 was 21 days for both groups; however, cycles of 22 or more days were significantly more common among patient who did not receive early G-CSF. Discontinuation of chemotherapy after cycle 1 was similarly prevalent in the two groups.

During cycle 1, there were 133 deaths, 72 (2.2\%) among patients who received early G-CSF and 61 (2.4\%) among those who did not receive G-CSF. The rates of death with and without infection did not differ significantly between those who received early G-CSF and those who did not (Table 3). The mean costs of inpatient and outpatient visits for infection were significantly higher among patients who received early G-CSFs, a reflection, perhaps, of their advanced age and residence in the Northeast and San Francisco (Table 3).
There was an inverse relationship between factors associated with early G-CSF use and rates of outpatient visits for infection; that is, the lowest rates of outpatient visits for infection were observed among patients with factors associated with the highest rates of early G-CSF use. Patients treated by hematologists, who had the highest rates of early G-CSF use, had the lowest rates of outpatient visits for infection compared with other specialties ( 33 vs $42 \% ; p<0.0001$ ) (Table 4$)$. The most dramatic example of this pattern was the impact of year of diagnosis. Visits for infection were most common (occurring in more than $50 \%$ of patients) in the early years of the study period when utilization of early GCSFs was lowest (26 to $43 \%$ ). Only advanced age showed a different pattern; elderly patients were more 
Table 3 Outcomes

\begin{tabular}{|c|c|c|c|c|c|}
\hline \multirow[t]{2}{*}{ Outcome } & \multicolumn{2}{|c|}{ With early G-CSF $(N=3294)$} & \multicolumn{2}{|c|}{ Without early G-CSF $(N=2590)$} & \multirow[t]{2}{*}{$p$ value } \\
\hline & Value & $95 \% \mathrm{CI}$ & Value & $95 \% \mathrm{CI}$ & \\
\hline \multicolumn{6}{|l|}{$\%$ with infection visit } \\
\hline Outpatient \% & 32.3 & $30.7-33.9$ & 44.9 & $43.0-46.9$ & $<0.0001$ \\
\hline Inpatient $\%$ & 5.2 & $4.4-6.0$ & 4.4 & $3.7-5.3$ & 0.1982 \\
\hline Either outpt or inpt $\%$ & 35.1 & $33.5-36.8$ & 46.7 & $44.8-48.7$ & $<0.0001$ \\
\hline \multicolumn{6}{|l|}{$\%$ who died } \\
\hline With infection & 3.8 & $2.8-5.1$ & 3.2 & $2.3-4.4$ & 0.5027 \\
\hline Without infection & 1.1 & $0.7-1.7$ & 1.3 & $0.8-2.1$ & 0.6363 \\
\hline \multicolumn{6}{|l|}{ Infection visit mean cost all pts } \\
\hline Outpatient mean cost (SD) & $\$ 166(\$ 946)$ & $\$ 0-\$ 23,253^{\mathrm{a}}$ & $\$ 113(\$ 493)$ & $\$ 0-\$ 10,459^{\mathrm{a}}$ & $<0.0001$ \\
\hline Inpatient mean cost (SD) & $\$ 1254(\$ 7137)$ & $\$ 0-\$ 208,122^{\mathrm{a}}$ & $\$ 951(\$ 6442)$ & $\$ 0-\$ 173,458^{\mathrm{a}}$ & 0.0189 \\
\hline Either visit mean cost (SD) & $\$ 1421(\$ 7227)$ & $\$ 0-\$ 208,180^{\mathrm{a}}$ & $\$ 1064(\$ 6466)$ & $\$ 0-\$ 173,458^{\mathrm{a}}$ & $<0.0001$ \\
\hline \multicolumn{6}{|c|}{ Infection visit mean cost pts with infection } \\
\hline Number of patients & 1268 & $\$ 0-\$ 23,253^{\mathrm{a}}$ & 1269 & $\$ 0-\$ 10,459^{\mathrm{a}}$ & $<0.0001$ \\
\hline Outpatient mean cost & $\$ 432(\$ 1488)$ & $\$ 0-\$ 208,122^{\mathrm{a}}$ & $\$ 231(\$ 685)$ & $\$ 0-\$ 173,458^{\mathrm{a}}$ & \\
\hline Inpatient mean cost & $\$ 3256(\$ 11,213)$ & $\$ 1-\$ 208,180^{\mathrm{a}}$ & $\$ 1940(\$ 9099)$ & $\$ 8-\$ 173,458^{\mathrm{a}}$ & \\
\hline Either visit mean cost & $\$ 3687(\$ 11,281)$ & & $\$ 2171(\$ 9106)$ & & \\
\hline \multicolumn{6}{|l|}{ Days to cycle 2} \\
\hline Median days (for pts with cycle 2) & 21 & $8-59^{\mathrm{b}}$ & 21 & $8-57^{\mathrm{b}}$ & $<0.0001$ \\
\hline$\%$ with $22-24$ days & 11.0 & $9.9-12.1$ & 14.2 & $12.9-15.6$ & 0.0002 \\
\hline$\%$ with $25-28$ days & 8.1 & $7.2-9.1$ & 11.3 & $10.1-12.6$ & $<0.0001$ \\
\hline$\%$ with $>28$ days & 6.8 & $6.0-7.7$ & 8.8 & $7.7-9.9$ & 0.0048 \\
\hline$\%$ with no cycle 2 & 10.4 & $9.4-11.5$ & 9.6 & $8.5-10.8$ & 0.3368 \\
\hline
\end{tabular}

${ }^{\text {a }}$ Standard deviation and minimum and maximum cost respectively

${ }^{\mathrm{b}}$ Minimum and maximum days to cycle 2

likely to receive early G-CSFs and similarly likely to have outpatient visits for infection. In contrast to outpatient visits for infection, inpatient visits for infection were associated only with male sex (6 vs $4 \%$; $p=0.009$ ), with higher comorbidity score (7 vs $4 \%$; $p=0.001)$, and with treatment in an institution-based practice ( 7 vs $2 \% ; p<0.0001)$.

Multiple-variable analyses revealed that patients who received early G-CSFs $(\mathrm{OR}=0.63 ; p<0.0001)$ and those who received rituximab $(\mathrm{OR}=0.70 ; p=0.0001)$ were significantly less likely to have an inpatient or outpatient visit for fever or infection as were those treated in institution-based practices $(\mathrm{OR}=0.76 ; p<0.0001)$ and practices in the West region $(\mathrm{OR}=0.83 ; p=0.02)$ and in Texas $(\mathrm{OR}=0.83 ; p=0.07)$ (Table 5 ). Older patients ( $\geq 80$ years) were significantly more likely to have an inpatient or outpatient visit for infection $(\mathrm{OR}=1.17 ; p=0.06)$.

\section{Discussion}

Granulocyte growth factors have been shown to be effective in reducing the depth and duration of chemotherapy-induced neutropenia as well as the risks of fever and infection during neutropenia [15]. Despite continuing controversy about which patients' risks of fever and infection justify the expense of these agents, primary prophylaxis with these agents is now recommended for all elderly patients with non-Hodgkin's lymphoma who undergo CHOP-based chemotherapy by professional societies in Europe [20, 21] and the USA [22, 23]. In our study, $56 \%$ of such patients treated between 2001 and 2007 received early G-CSFs; however, utilization increased significantly over time as published evidence specific to this population accumulated.

The first guideline recommending primary prophylaxis with G-CSFs of all elderly patients with NHL receiving CHOP-based chemotherapy was published by the EORTC Cancer in the Elderly Task Force in late 2003 [24]. In the USA, the first recommendation was published by NCCN in 2004 [17], shortly after publication of two randomized clinical trials (in 2003) showing effectiveness in this population [13, 14]. These publications were followed by a pronounced increase in G-CSF use in this population although it is not possible to determine whether the change in practice was due to the guidelines, the clinical trials, or both. Adherence to guidelines after their publication exceeded $70 \%$. 
Table 4 Probability of outpatient or hospital visits for infection (TCR + SEER)

\begin{tabular}{|c|c|c|c|c|c|}
\hline Factor & $\begin{array}{l}\text { Number } \\
\text { of patients }\end{array}$ & $\begin{array}{l}\text { \% with outpatient visit } \\
(95 \% \mathrm{CI})\end{array}$ & $p$ value & $\begin{array}{l}\text { \% with hospital visit } \\
(95 \% \mathrm{CI})\end{array}$ & $p$ value \\
\hline \multicolumn{6}{|l|}{ Early G-CSF } \\
\hline Yes & 3294 & $32.3 \%(30.7-33.9 \%)$ & \multirow[t]{2}{*}{$<0.0001$} & $5.2 \%(4.4-6.0 \%)$ & \multirow[t]{2}{*}{0.1982} \\
\hline No & 2590 & $44.9 \%(43.0-46.9 \%)$ & & $4.4 \%(3.7-5.3 \%)$ & \\
\hline \multicolumn{6}{|l|}{ Age (years) } \\
\hline$<70$ & 1171 & $37.7 \%(34.9-40.5 \%)$ & \multirow[t]{4}{*}{0.7612} & $3.6 \%(2.6-4.9 \%)$ & \multirow[t]{4}{*}{0.1180} \\
\hline $70-79$ & 1654 & $37.0 \%(34.7-39.4 \%)$ & & $4.8 \%(3.8-6.0 \%)$ & \\
\hline $80-85$ & 1540 & $38.8 \%(36.4-41.3 \%)$ & & $5.1 \%(4.1-6.4 \%)$ & \\
\hline$>85$ & 1519 & $38.0 \%(35.6-40.5 \%)$ & & $5.5 \%(4.5-6.8 \%)$ & \\
\hline \multicolumn{6}{|l|}{ Race } \\
\hline White & 5406 & $38.0 \%(36.7-39.3 \%)$ & \multirow[t]{3}{*}{0.2275} & $4.9 \%(4.4-5.5 \%)$ & \multirow[t]{3}{*}{0.4837} \\
\hline Black & 181 & $40.9 \%(33.7-48.4 \%)$ & & $5.0 \%(2.4-9.5 \%)$ & \\
\hline Others & 297 & $33.7 \%(28.4-39.4 \%)$ & & $3.4 \%(1.7-6.3 \%)$ & \\
\hline \multicolumn{6}{|l|}{ Sex } \\
\hline Male & 2764 & $36.6 \%(34.8-38.4 \%)$ & \multirow[t]{2}{*}{0.0632} & $5.6 \%(4.8-6.6 \%)$ & \multirow[t]{2}{*}{0.0088} \\
\hline Female & 3120 & $39.0 \%(37.3-40.7 \%)$ & & $4.1 \%(3.5-4.9 \%)$ & \\
\hline \multicolumn{6}{|l|}{ Ethnicity } \\
\hline Hispanic & 432 & $33.8 \%(29.4-38.5 \%)$ & \multirow[t]{3}{*}{0.1075} & $5.6 \%(3.7-8.3 \%)$ & \multirow[t]{3}{*}{0.3303} \\
\hline Non-Hispanic & 5383 & $38.3 \%(37.0-39.6 \%)$ & & $4.8 \%(4.3-5.4 \%)$ & \\
\hline Unknown & 69 & $37.9 \%(21.5-44.3 \%)$ & & & \\
\hline \multicolumn{6}{|l|}{ Comorbidity score } \\
\hline $0-1$ & 5124 & $38.1 \%(36.8-39.5 \%)$ & \multirow[t]{2}{*}{0.3166} & $4.5 \%(3.9-5.1 \%)$ & 0.0010 \\
\hline$\geq 2$ & 760 & $36.2 \%(32.8-39.7 \%)$ & & $7.4 \%(5.7-9.5 \%)$ & \\
\hline State buy-in & & & & & \\
\hline Yes & 685 & $37.7 \%(34.0-41.4 \%)$ & 0.9332 & $4.7 \%(3.3-6.6 \%)$ & 0.9245 \\
\hline No & 5199 & $37.9 \%(36.6-39.2 \%)$ & & $4.9 \%(4.3-5.5 \%)$ & \\
\hline Residence & & & & & \\
\hline Non-metropolitan area & 1013 & $35.8 \%(32.9-38.9 \%)$ & 0.1446 & $4.8 \%(3.6-6.4 \%)$ & 1.0000 \\
\hline Metropolitan area & 4871 & $38.3 \%(36.9-39.7 \%)$ & & $4.8 \%(4.2-5.5 \%)$ & \\
\hline Rituximab treatment & & & & & \\
\hline No & 519 & $48.6 \%(44.2-52.9 \%)$ & $<0.0001$ & $3.5 \%(2.1-5.5 \%)$ & 0.1620 \\
\hline Yes & 5365 & $36.8 \%(35.5-38.1 \%)$ & & $5.0 \%(4.4-5.6 \%)$ & \\
\hline Quartile of $\%$ persons $25+$ & n high schoo & on $^{\mathrm{a}}$ & & & \\
\hline$\leq 8.17 \%$ & 1465 & $37.1 \%(34.7-39.7 \%)$ & 0.4675 & $4.2 \%(3.3-5.4 \%)$ & 0.3734 \\
\hline $8.18-14.53 \%$ & 1462 & $37.6 \%(35.1-40.1 \%)$ & & $4.7 \%(3.7-6.0 \%)$ & \\
\hline $14.54-24.56 \%$ & 1460 & $37.4 \%(34.9-40.0 \%)$ & & $5.6 \%(4.5-7.0 \%)$ & \\
\hline$>24.56 \%$ & 1462 & $39.7 \%(37.2-42.2 \%)$ & & $4.9 \%(3.8-6.1 \%)$ & \\
\hline Quartile of $\%$ persons $25+$ & me college e & & & & \\
\hline$\leq 13.02 \%$ & 1464 & $40.0 \%(37.5-42.6 \%)$ & 0.1857 & $5.7 \%(4.6-7.0 \%)$ & 0.1381 \\
\hline $13.03-22.92 \%$ & 1461 & $36.6 \%(34.2-39.2 \%)$ & & $5.3 \%(4.2-6.6 \%)$ & \\
\hline $22.93-39.60 \%$ & 1462 & $36.7 \%(34.3-39.3 \%)$ & & $4.5 \%(3.5-5.7 \%)$ & \\
\hline$>39.60 \%$ & 1462 & $38.4 \%(35.9-40.9 \%)$ & & $4.0 \%(3.1-5.1 \%)$ & \\
\hline Quartile of tract residents & low poverty & & & & \\
\hline$\leq 4.13 \%$ & 1465 & $38.1 \%(35.6-40.6 \%)$ & 0.6610 & $4.6 \%(3.6-5.8 \%)$ & 0.8962 \\
\hline $4.14-7.69 \%$ & 1463 & $37.4 \%(34.9-39.9 \%)$ & & $5.1 \%(4.1-6.4 \%)$ & \\
\hline $7.70-14.31 \%$ & 1461 & $37.1 \%(34.6-39.6 \%)$ & & $5.0 \%(4.0-6.3 \%)$ & \\
\hline$>14.31 \%$ & 1460 & $39.2 \%(36.7-41.7 \%)$ & & $4.7 \%(3.7-6.0 \%)$ & \\
\hline Facility & & & & & \\
\hline Institution based & 3453 & $33.7 \%(32.1-35.3 \%)$ & $<0.0001$ & $7.0 \%(6.2-8.0 \%)$ & $<0.0001$ \\
\hline Not institution based & 2431 & $43.8 \%(41.8-45.8 \%)$ & & $1.7 \%(1.2-2.3 \%)$ & \\
\hline Board certification & & & & & \\
\hline Medical oncology & 2765 & $39.1 \%(37.2-40.9 \%)$ & $<0.0001$ & $4.8 \%(4.0-5.7 \%)$ & 0.7932 \\
\hline Hematology & 1471 & $32.8 \%(30.4-35.3 \%)$ & & $4.6 \%(3.6-5.8 \%)$ & \\
\hline Internal medicine & 454 & $36.3 \%(31.9-41.0 \%)$ & & $4.6 \%(3.0-7.1 \%)$ & \\
\hline Others/unknown ${ }^{\mathrm{b}}$ & 1194 & $41.9 \%(39.1-44.7 \%)$ & & $5.4 \%(4.2-6.8 \%)$ & \\
\hline No. of elderly NHL pts tre & & & & & \\
\hline$<3$ pts per year & 4770 & $38.3 \%(36.9-39.7 \%)$ & 0.1596 & $4.7 \%(4.1-5.4 \%)$ & 0.4373 \\
\hline$\geq 3$ pts per year & 1114 & $36.0 \%(33.2-38.9 \%)$ & & $5.3 \%(4.1-6.8 \%)$ & \\
\hline
\end{tabular}


Table 4 (continued)

\begin{tabular}{|c|c|c|c|c|c|}
\hline Factor & $\begin{array}{l}\text { Number } \\
\text { of patients }\end{array}$ & $\begin{array}{l}\% \text { with outpatient visit } \\
(95 \% \mathrm{CI})\end{array}$ & $p$ value & $\begin{array}{l}\% \text { with hospital visit } \\
(95 \% \mathrm{CI})\end{array}$ & $p$ value \\
\hline \multicolumn{6}{|c|}{ Elderly NHL pts receiving chemo } \\
\hline $\begin{array}{l}<3 \text { pts per year } \\
\geq 3 \text { pts per year }\end{array}$ & $\begin{array}{l}4880 \\
1004\end{array}$ & $\begin{array}{l}38.4 \%(37.0-39.8 \%) \\
35.3 \%(32.3-38.3 \%)\end{array}$ & 0.0633 & $\begin{array}{l}4.7 \%(4.1-5.3 \%) \\
5.7 \%(4.4-7.3 \%)\end{array}$ & 0.1695 \\
\hline \multicolumn{6}{|l|}{ Tumor registry } \\
\hline $\begin{array}{l}\text { San Francisco } \\
\text { Connecticut } \\
\text { Detroit } \\
\text { Hawaii } \\
\text { Iowa } \\
\text { New Mexico } \\
\text { Seattle } \\
\text { Utah } \\
\text { Atlanta } \\
\text { San Jose } \\
\text { Los Angeles } \\
\text { Rural Georgia } \\
\text { Greater California } \\
\text { Kentucky } \\
\text { Louisiana } \\
\text { New Jersey } \\
\text { Texas }\end{array}$ & $\begin{array}{l}173 \\
305 \\
380 \\
77 \\
430 \\
123 \\
297 \\
175 \\
133 \\
116 \\
355 \\
-\mathrm{c} \\
948 \\
363 \\
354 \\
887 \\
757\end{array}$ & $\begin{array}{l}31.2 \%(24.5-38.8 \%) \\
43.9 \%(38.3-49.7 \%) \\
38.2 \%(33.3-43.3 \%) \\
27.3 \%(18.0-38.8 \%) \\
39.8 \%(35.1-44.6 \%) \\
39.0 \%(30.5-48.3 \%) \\
30.3 \%(25.2-35.9 \%) \\
47.4 \%(39.9-55.1 \%) \\
48.1 \%(39.4-56.9 \%) \\
31.0 \%(23.0-40.4 \%) \\
42.5 \%(37.4-47.9 \%) \\
{ }^{c} \\
35.7 \%(32.6-38.8 \%) \\
42.4 \%(37.3-47.7 \%) \\
35.0 \%(30.1-40.3 \%) \\
38.3 \%(35.1-41.6 \%) \\
35.8 \%(32.4-39.4 \%)\end{array}$ & 0.0001 & $\begin{array}{l}2.3 \%(0.7-6.2 \%) \\
5.3 \%(3.1-8.6 \%) \\
7.1 \%(4.8-10.3 \%) \\
2.6 \%(0.5-9.9 \%) \\
4.4 \%(2.8-6.9 \%) \\
5.7 \%(2.5-11.8 \%) \\
4.7 \%(2.7-8.0 \%) \\
6.3 \%(3.3-11.3 \%) \\
3.0 \%(1.0-8.0 \%) \\
7.8 \%(3.8-14.6 \%) \\
3.7 \%(2.1-6.3 \%) \\
{ }^{c} \quad \\
5.1 \%(3.8-6.7 \%) \\
6.3 \%(4.2-9.5 \%) \\
3.7 \%(2.1-6.4 \%) \\
5.0 \%(3.7-6.7 \%) \\
4.0 \%(2.7-5.7 \%)\end{array}$ & 0.3392 \\
\hline \multicolumn{6}{|l|}{ Region } \\
\hline $\begin{array}{l}\text { Northeast } \\
\text { Midwest } \\
\text { South } \\
\text { West } \\
\text { Texas }\end{array}$ & $\begin{array}{l}1192 \\
810 \\
861 \\
2264 \\
757\end{array}$ & $\begin{array}{l}39.8 \%(37.0-42.6 \%) \\
39.0 \%(35.7-42.5 \%) \\
40.2 \%(36.9-43.6 \%) \\
36.3 \%(34.3-38.3 \%) \\
35.8 \%(32.4-39.4 \%)\end{array}$ & 0.0881 & $\begin{array}{l}5.0 \%(3.9-6.5 \%) \\
5.7 \%(4.2-7.6 \%) \\
4.7 \%(3.4-6.3 \%) \\
4.8 \%(4.0-5.8 \%) \\
4.0 \%(2.7-5.7 \%)\end{array}$ & 0.6095 \\
\hline \multicolumn{6}{|l|}{ Diagnosis Year } \\
\hline $\begin{array}{l}2001 \\
2002 \\
2003 \\
2004 \\
2005 \\
2006 \\
2007\end{array}$ & $\begin{array}{l}703 \\
795 \\
862 \\
883 \\
876 \\
893 \\
872\end{array}$ & $\begin{array}{l}54.9 \%(51.1-58.6 \%) \\
60.6 \%(57.1-64.0 \%) \\
61.1 \%(57.8-64.4 \%) \\
58.2 \%(54.9-61.5 \%) \\
20.6 \%(18.0-23.4 \%) \\
8.6 \%(6.9-10.7 \%) \\
7.1 \%(5.5-9.1 \%)\end{array}$ & $<0.0001$ & $\begin{array}{l}3.8 \%(2.6-5.6 \%) \\
6.7 \%(5.1-8.7 \%) \\
4.1 \%(2.9-5.7 \%) \\
4.4 \%(3.2-6.1 \%) \\
5.1 \%(3.8-6.9 \%) \\
4.6 \%(3.4-6.2 \%) \\
5.1 \%(3.7-6.8 \%)\end{array}$ & 0.1651 \\
\hline
\end{tabular}

a 35 patients with missing value

${ }^{\mathrm{b}}<11$ patients with unknown of the specialty type; exact number suppressed to protect confidentiality

${ }^{\mathrm{c}}$ Values suppressed due to small number of patients

We found that the rapid increase in the use of early G-CSFs in 2004 and following years was associated with a large and rapid decline in outpatient visits for fever and infection (Figure 1). These results demonstrate the effectiveness of granulocyte growth factors in preventing febrile neutropenia and infections in a large population-based sample. Most clinical trials report only grades 3 or 4 adverse events; thus, infections treated in the outpatient setting may be underreported. However, a previous population-based study using SEER Medicare data in a similar population found significantly reduced risks of febrile neutropenia among elderly patients who received G-CSFs [25].
Retrospective reviews of 50 and 65 elderly patients receiving CHOP with or without G-CSF also support this finding $[26,27]$.

The prevalence of inpatient visits for fever or infection was unchanged over time and unrelated to G-CSF use, perhaps reflecting the importance of patient factors in the decision to hospitalize for therapy of fever or infection. The risk of death was also stable over time and unrelated to G-CSF use. These findings are consistent with those reported by Doorduijn and colleagues from a European cooperative group trial. They found that administration of G-CSFs improved relative dose intensity but had no impact on the risk of severe 
Table 5 Multiple-variable model of risk of either outpatient or inpatient visit for fever or infection

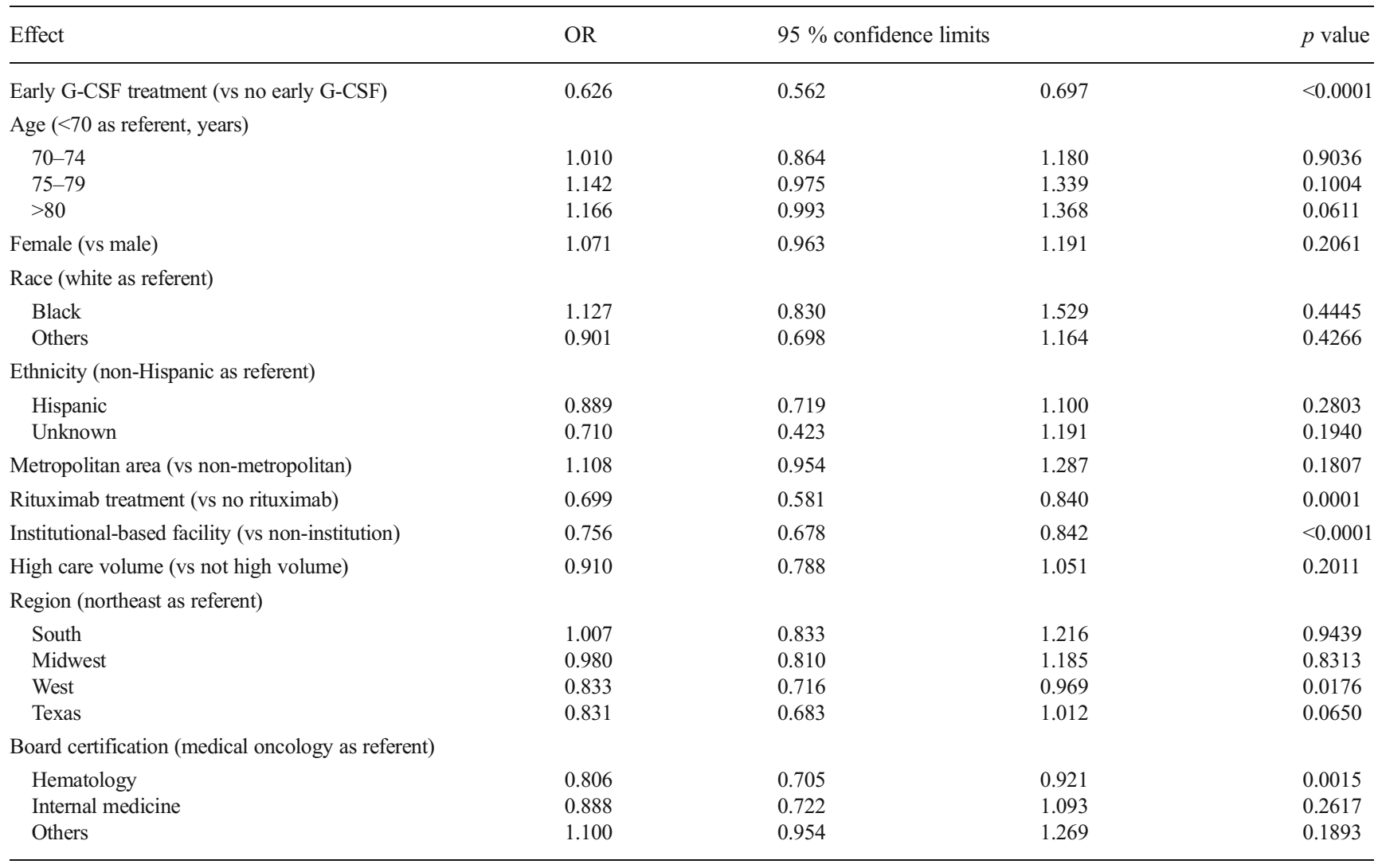

Model includes all demographic factors and other factors with $p<0.20$ in the univariate analysis

infection or on survival [14]. In contrast, Osby and colleagues reported significantly fewer episodes of infection requiring hospitalization among elderly patients with NHL who received G-CSFs with CHOP-based chemotherapy [13]. However, they also found no impact of G-CSF administration on survival.
Fig. 1 Relationship between inpatient or outpatient infections and the use of G-CSFs

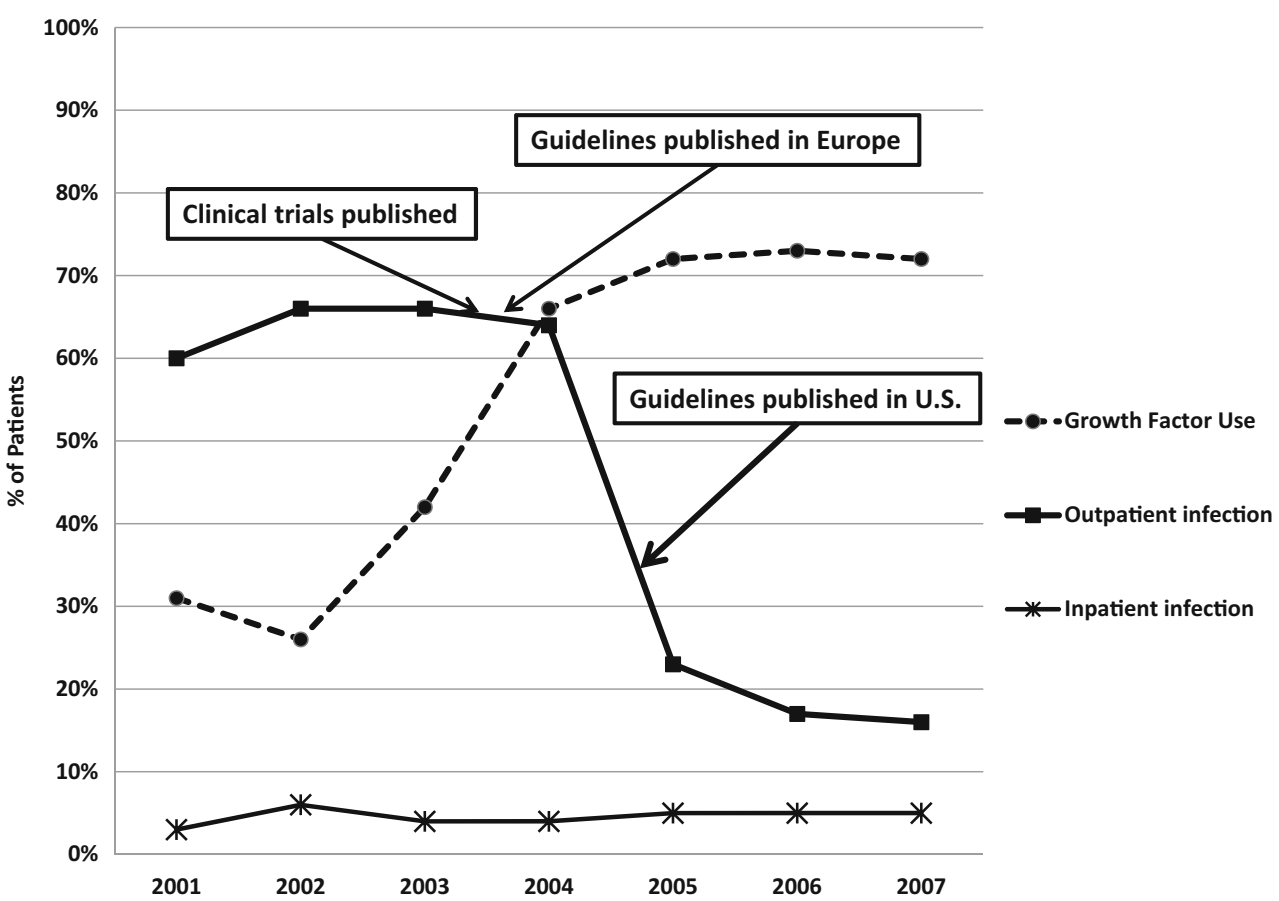




\section{Limitations}

Among the strengths of this study are its population basis and large size. The findings are likely to be representative of practice and outcomes in the USA. Further, the large sample of elderly patients, who are often underrepresented in clinical trials, provides insight into this under-studied population. However, the study's limitations should be considered when interpreting these results. All analyses using claims are subject to coding errors, both over- and under-coding. Beyond these common problems are two limitations of this analysis. First, treatment intent cannot be discerned from claims data, and, thus, we defined primary prophylaxis by the timing of G-CSF administration. It is possible that our use of 7 days for this definition included some instances of GCSF treatment for early infection rather than prophylaxis. If this occurred, our results would be biased toward no difference between those who received G-CSF and those who did not. Second, G-CSF use was at the discretion of the physician not a result of random assignment. Consequently, prescription of G-CSFs may have been subject to bias by confounding factors such as advanced age, debility, and comorbidity. It is not possible to determine what direction this bias takes. For example, physicians could have prescribed G-CSFs among the sickest, oldest patients or alternatively, among those in whom they intended to use the highest chemotherapy doses. We have attempted to control for these factors in multiple-variable analysis by including age and comorbidity scores. However, it is unlikely that these measures would control this bias completely.

\section{Conclusions}

We conclude that adherence to guidelines for G-CSFs use among elderly patients with NHL who receive CHOP-based regimens is quite good in the USA, exceeding $70 \%$. Adherence to these guidelines results in significantly reduced risks of fever and infection compared with patients who do not receive early G-CSFs. However, neither the risk of serious infections requiring hospitalization nor survival is affected by the use of early G-CSF.

Acknowledgments This work was supported by the Comparative Effectiveness Research on Cancer in Texas (CERCIT) Grant no. RP140020, funded by The Cancer Prevention Research Institute of Texas (CPRIT) and by the Duncan Family Institute.

This study used the linked SEER-Medicare database. The interpretation and reporting of these data are the sole responsibility of the authors. The authors acknowledge the efforts of the Applied Research Program, NCI; the Office of Research,
Development and Information, CMS; Information Management Services (IMS), Inc.; and the Surveillance, Epidemiology, and End Results (SEER) Program tumor registries in the creation of the SEER-Medicare database.

In addition to SEER-Medicare, some of the cancer incidence data used in this study was supported by the Texas Department of State Health Services and CPRIT, as part of the statewide cancer reporting program, and the Centers for Disease Control and Prevention's National Program of Cancer Registries Cooperative Agreement \#5U58/DP000824-05. Its contents are solely the responsibility of the authors and do not necessarily represent the official views of the DSHS, CPRIT, or CDC.

Compliance with ethical standards This study was approved by the Institutional Review Boards of MD Anderson Cancer Center and the Texas Department of State Health Services.

Conflict of interest Dr. Chavez-Macgregor has a consultancy agreement with Amgen, for research on the use of bisphosphonates. With that exception, the authors declare that they have no competing interests.

\section{References}

1. Tirelli U, Zagonel V, Serraino D, Thomas J, Hoerni B, Tangury A, Ruhl U, Bey P, Tubiana N, Breed WP et al (1988) Non-Hodgkin's lymphomas in 137 patients aged 70 years or older: a retrospective European Organization for Research and Treatment of Cancer Lymphoma Group Study. J Clin Oncol 6(11):1708-1713

2. Armitage JO, Potter JF (1984) Aggressive chemotherapy for diffuse histiocytic lymphoma in the elderly: increased complications with advancing age. J Am Geriatr Soc 32(4):269-273

3. Vose JM, Armitage JO, Weisenburger DD, Bierman PJ, Sorensen S, Hutchins M, Moravec DF, Howe D, Dowling MD, Mailliard J et al (1988) The importance of age in survival of patients treated with chemotherapy for aggressive non-Hodgkin's lymphoma. J Clin Oncol 6(12):1838-1844

4. Fisher RI, Gaynor ER, Dahlberg S, Oken MM, Grogan TM, Mize EM, Glick JH, Coltman CA Jr, Miller TP (1993) Comparison of a standard regimen (CHOP) with three intensive chemotherapy regimens for advanced non-Hodgkin's lymphoma. N Engl J Med 328(14):1002-1006. doi:10.1056/nejm199304083281404

5. Tirelli U, Errante D, Van Glabbeke M, Teodorovic I, KluinNelemans JC, Thomas J, Bron D, Rosti G, Somers R, Zagonel V, Noordijk EM (1998) CHOP is the standard regimen in patients $>$ or $=70$ years of age with intermediate-grade and high-grade nonHodgkin's lymphoma: results of a randomized study of the European Organization for Research and Treatment of Cancer Lymphoma Cooperative Study Group. J Clin Oncol 16(1):27-34

6. Coiffier B, Lepage E, Briere J, Herbrecht R, Tilly H, Bouabdallah R, Morel P, Van Den Neste E, Salles G, Gaulard P, Reyes F, Lederlin P, Gisselbrecht C (2002) CHOP chemotherapy plus rituximab compared with CHOP alone in elderly patients with diffuse large-B-cell lymphoma. N Engl J Med 346(4):235-242. doi:10. 1056/NEJMoa011795

7. Grann VR, Hershman D, Jacobson JS, Tsai WY, Wang J, McBride R, Mitra N, Grossbard ML, Neugut AI (2006) Outcomes and diffusion of doxorubicin-based chemotherapy among elderly patients with aggressive non-Hodgkin lymphoma. Cancer 107(7):1530 1541. doi:10.1002/cncr.22188

8. Morrison VA, Picozzi V, Scott S, Pohlman B, Dickman E, Lee M, Lawless G, Kerr R, Caggiano V, Delgado D, Fridman M, Ford J, 
Carter WB (2001) The impact of age on delivered dose intensity and hospitalizations for febrile neutropenia in patients with intermediate-grade non-Hodgkin's lymphoma receiving initial CHOP chemotherapy: a risk factor analysis. Clin Lymphoma 2(1):47-56

9. Chrischilles E, Delgado DJ, Stolshek BS, Lawless G, Fridman M, Carter WB (2002) Impact of age and colony-stimulating factor use on hospital length of stay for febrile neutropenia in CHOP-treated non-Hodgkin's lymphoma. Cancer Control 9(3):203-211

10. Chen-Hardee S, Chrischilles EA, Voelker MD, Brooks JM, Scott S, Link BK, Delgado D (2006) Population-based assessment of hospitalizations for neutropenia from chemotherapy in older adults with non-Hodgkin's lymphoma (United States). Cancer Causes Control 17(5):647-654. doi:10.1007/s10552-005-0502-4

11. Dixon DO, Neilan B, Jones SE, Lipschitz DA, Miller TP, Grozea PN, Wilson HE (1986) Effect of age on therapeutic outcome in advanced diffuse histiocytic lymphoma: the Southwest Oncology Group experience. J Clin Oncol 4(3):295-305

12. Lyman GH, Dale DC, Friedberg J, Crawford J, Fisher RI (2004) Incidence and predictors of low chemotherapy dose-intensity in aggressive non-Hodgkin's lymphoma: a nationwide study. J Clin Oncol 22(21):4302-4311. doi:10.1200/jco.2004.03.213

13. Osby E, Hagberg H, Kvaloy S, Teerenhovi L, Anderson H, Cavallin-Stahl E, Holte H, Myhre J, Pertovaara H, Bjorkholm M (2003) CHOP is superior to CNOP in elderly patients with aggressive lymphoma while outcome is unaffected by filgrastim treatment: results of a Nordic Lymphoma Group randomized trial. Blood 101(10):38403848. doi:10.1182/blood-2002-10-3238

14. Doorduijn JK, van der Holt B, van Imhoff GW, van der Hem KG, Kramer MH, van Oers MH, Ossenkoppele GJ, Schaafsma MR, Verdonck LF, Verhoef GE, Steijaert MM, Buijt I, Uyl-de Groot CA, van Agthoven M, Mulder AH, Sonneveld P (2003) CHOP compared with CHOP plus granulocyte colony-stimulating factor in elderly patients with aggressive non-Hodgkin's lymphoma. J Clin Oncol 21(16):3041-3050. doi:10.1200/jco.2003.01.076

15. Wang L, Baser O, Kutikova L, Page JH, Barron R (2015) The impact of primary prophylaxis with granulocyte colonystimulating factors on febrile neutropenia during chemotherapy: a systematic review and meta-analysis of randomized controlled trials. Support Care Cancer. doi:10.1007/s00520-015-2686-9

16. Smith TJ, Khatcheressian J, Lyman GH, Ozer H, Armitage JO, Balducci L, Bennett CL, Cantor SB, Crawford J, Cross SJ, Demetri G, Desch CE, Pizzo PA, Schiffer CA, Schwartzberg L, Somerfield MR, Somlo G, Wade JC, Wade JL, Winn RJ, Wozniak AJ, Wolff AC (2006) 2006 update of recommendations for the use of white blood cell growth factors: an evidence-based clinical practice guideline. J Clin Oncol 24(19):3187-3205. doi:10. 1200/jco.2006.06.4451

17. Balducci L (2004) NCCN Senior Adult Oncology Panel Report. J Natl Compr Canc Netw 2(Suppl 3):S-42-45
18. Howlander N, Noone A, Krapcho M, al. E (2014) SEER Cancer Statistics Review 1975-2011. National Cancer Institute. http://seer. cancer.gov/csr/1975_2011/

19. Potosky ALRG, Lubitz JD et al (1993) Potential for cancer related health services research using a linked Medicare-tumor registry database. Med Care 31:732-748

20. Crawford J, Caserta C, Roila F (2010) Hematopoietic growth factors: ESMO clinical practice guidelines for the applications. Ann Oncol 21(Suppl 5):v248-251. doi:10.1093/annonc/mdq195

21. Aapro MS, Bohlius J, Cameron DA, Dal Lago L, Donnelly JP, Kearney N, Lyman GH, Pettengell R, Tjan-Heijnen VC, Walewski J, Weber DC, Zielinski C (2011) 2010 update of EORTC guidelines for the use of granulocyte-colony stimulating factor to reduce the incidence of chemotherapy-induced febrile neutropenia in adult patients with lymphoproliferative disorders and solid tumours. Eur J Cancer (Oxford, England : 1990) 47(1):832. doi:10.1016/j.ejca.2010.10.013

22. Smith TJ, Bohlke K, Lyman GH, Carson KR, Crawford J, Cross SJ, Goldberg JM, Khatcheressian JL, Leighl NB, Perkins CL, Somlo G, Wade JL, Wozniak AJ, Armitage JO (2015) Recommendations for the use of WBC growth factors: American Society of Clinical Oncology clinical practice guideline update. J Clin Oncol. doi:10.1200/jco. 2015.62.3488

23. Balducci L (2015) NCCN Senior Adult Oncology Available via NLM. http://www.ncen.org/professionals/physician_gls/ pdf/senior.pdf

24. Repetto L, Biganzoli L, Koehne CH, Luebbe AS, Soubeyran P, Tjan-Heijnen VC, Aapro MS (2003) EORTC Cancer in the Elderly Task Force guidelines for the use of colony-stimulating factors in elderly patients with cancer. Eur J Cancer (Oxford, England : 1990) 39(16):2264-2272

25. Gruschkus SK, Lairson D, Dunn JK, Risser J, Du XL (2010) Comparative effectiveness of white blood cell growth factors on neutropenia, infection, and survival in older people with nonHodgkin's lymphoma treated with chemotherapy. J Am Geriatr Soc 58(10):1885-1895. doi:10.1111/j.1532-5415.2010.03081.x

26. Lee S, Knox A, Zeng IS, Coomarasamy C, Blacklock H, Issa S (2013) Primary prophylaxis with granulocyte colony-stimulating factor (GCSF) reduces the incidence of febrile neutropenia in patients with non-Hodgkin lymphoma (NHL) receiving CHOP chemotherapy treatment without adversely affecting their quality of life: cost-benefit and quality of life analysis. Support Care Cancer 21(3):841-846. doi:10.1007/s00520-012-1589-2

27. Donnelly GB, Glassman J, Long C, Torres P, Straus DJ, O'Brien JP, Bertino J, Moskowitz CH, Zelenetz AD, Portlock CS (2000) Granulocyte-colony stimulating factor (G-CSF) may improve disease outcome in elderly patients with diffuse large cell lymphoma (DLCL) treated with CHOP chemotherapy. Leuk Lymphoma 39(12):67-75. doi:10.3109/10428190009053540 